\title{
Situated Ethics in Investigating Non-Government Organisations and Showgrounds: Issues in Researching Japanese Environmental Politics and Australian Traveller Education
}

\author{
Mike Danaher (m.danaher@cqu.edu.au) \\ Faculty of Arts, Humanities and Education, Central Queensland University, Australia
}

and

P. A. Danaher (danaher@usq.edu.au)

Faculty of Education and Centre for Research in Transformative Pedagogies, University of Southern Queensland, Australia

This article has been anonymously peer-reviewed and accepted for publication in the International Journal of

Pedagogies and Learning, an international, peer-reviewed journal that focuses on issues and trends in pedagogies and learning in national and international contexts. ISSN 1833-4105.

(C) Copyright of articles is retained by authors. As this is an open access journal, articles are free to use, with proper attribution, in educational and other non-commercial settings.

\begin{abstract}
Situated ethics (Piper \& Simons, 2005; Simons \& Usher, 2000) provides a potentially powerful conceptual lens for reflecting on the research significance and researcher subjectivities entailed in contemporary educational research projects. This is the idea that research ethics is most appropriately understood and enacted in the specific contexts of such projects, rather than by reference to timeless and universal codes. This proposition is helpful in drawing attention to the crucial networks of aspirations and interests that bind and separate stakeholders in those projects.
\end{abstract}

The authors illustrate this argument through a reflexive interrogation of their respective empirical doctoral studies (Danaher, 2003; Danaher, 2001). One study focused on multiple and conflicting constructions of wildlife preservation as a site of Japanese environmental politics and policy-making; the other examined educational provision for mobile show communities as a case of Australian Traveller Education. Both projects required the researchers to negotiate tentative and sometimes uneasy relations with research participants that veered between impartial and disinterested observers and partial and interested advocates. In engaging in those negotiations, the researchers enacted situated and provisional ethical positions derived from increasingly explicit assumptions about both the significance of their particular research and the importance of acknowledging their own subjectivities in making claims about that significance. Thus situated ethics is a vital element of evaluating the value as much as the values of conducting research with non-government organisations and on showgrounds. 


\section{Introduction}

We begin with a vignette from each of our empirical research projects (one Japanese, one Australian):

Vignette 1

$T$ he A ustralian environmental researcher sat at his trusty (and rusty) PC, gazing at the blank screen and waiting for inspiration to strike. $T$ his time it wasn't the latest chapter of his P hD thesis about I apanese environmental politics, centred on the whaling debate, that he was urging to appear - that was safely in the hands of his supervisor. Instead it was the first draft of a chapter (D anaher, 2004) of an edited book about educational research ethics, politics and risk. $T$ he researcher felt a bit of an outsider in the project, although he could see so me potentially fruitful links between the book's focus and the educational implications of the main argument in his thesis. W hat was preventing the $P C$ screen from filling up magically with words of wisdom was not writer's block but instead the recollection of two separate meetings that had occurred coincidentally in the same week of a research trip to J apan.

T he first of these visits had been to the $T$ o kyo office of $G$ reenpeace, where he'd conducted a focus group interview with four members of that organisation - one J ap anese, two from the $U$ nited $S$ tates and the other a fellow A ustralian. $H$ e'd been gratified that they'd given him so much collective time - an hour's audio taped discussion - and their passionate anti-whaling stance accorded instinctively with his own lifelong love of animals. $H$ e'd found it difficult to avo id slipping out of the 'researcher-questioner' role and sharing ideas for future campaigns.

T he second visit had occurred at the end of the same week, also in T o kyo but this time with an official from the J apanese F isheries A gency. W hile some of his colleagues had interp reted often rather intemperately - anti-whaling as an affront to I apan's cultural history and national sovereignty, this official was far mo re measured. A s an alternative he highlighted I ap an's lack of natural resources, its dependence on seafood in its diet and the impact on other species of unchecked growth in whale numbers.

T he juxtaposition within the same week of the two meetings with representatives of two organisations with two diametrically opposed viewpoints reminded the researcher of his initial culture shock on his first trip to I apan. S o many different experiences had challenged his taken for granted assumptions - including his anti-whaling stance - that he had felt disoriented and uncertain. $N$ ot that he was now an advocate for whaling. Instead he "would like to see [him]self as a balanced researcher" ( $D$ anaher, 2004, p. 122) and he is "striving to enhance understandings of the political co mplexities of the whaling debate, a subject that is not commonly und ersto $0 \mathrm{~d}$ " ( $p$. 118).

\section{Vignette 2}

The five educational researchers - four on one campus, the fifth at another campus, of the same university where they had worked together for the past eight years - sat huddled around the speaker telephone in their respective meeting rooms. The discussion had an air of urgency, even of desperation: they were having to confront what at the time seemed a difficult ethical dilemma. For 
several of those eight years they had engaged in qualitative data gathering with members of the Australian show community, whose formal Traveller education at the time was centred on their children's enrolment in the Brisbane School of Distance Education. This institution focused on distance education for children living on properties and working with hometutors and since 1989 had developed a specialised program for the show children.

The meeting had been prompted by a phone call to one of the researchers from a leading member of the Showmen's Guild of Australasia. The Guild had been successful in initiating a meeting with Education Queensland to discuss the Guild's lobbying for a separate school for show children, under the auspices of Education Queensland. The Guild wanted the researcher to fly to Brisbane for the meeting, which was to take place in a couple of days' time. The researcher's role was to present the results of the ongoing research project and presumably to lend the research team's endorsement to the idea of the separate school.

The research team were in a quandary. They knew and respected many members of the Guild for their unquestioned commitment to their children's education. They also knew and had good relations with the principal of the Brisbane School of Distance Education and doubted that he would be pleased about the proposal. As well they knew that one of the teachers from the school working with the children had close connections with the Guild members. They could sense a potential conflict involving interpersonal and interagency relationships in which they were marginal but that were vital to their continuing connections with the participants in their research project.

In the end the researcher flew to Brisbane to attend the meeting. The Guild members had planned the discussion carefully and spoke persuasively to the attending Education Queensland officials, who like good officials were polite and interested but noncommittal. The researcher spoke briefly and showed the officials the videotape that his colleagues and he had made a few years previously about the show children's education. However, as he received after the meeting from a Guild member a cheque to cover the cost of his flight he wondered if they had got their money's worth from the trip.

In retrospect, it's difficult to recall what prompted the researchers' unease. The show community received approval for a separate school - the Queensland School for Travelling Show Children began operating in 2000. On the other hand, whether the meeting with Education Queensland had any bearing on that approval is a moot point. (Similarly, whether the researchers can claim to have contributed to the school's establishment as part of the quality and impact of their research to satisfy the former Australian Research Qual ity Framework is likewise contentious). The researchers have maintained friendly relations with the now retired principal of the Brisbane School of Distance Education. The aforementioned teacher from that school became the show school's inaugural principal. And the researchers have conducted follow up research with the school staff and the show community to see how having their own school has influenced their educational aspirations and outcomes (Moriarty, Danaher, Kenny \& Danaher, 2004).

There are clearly important differences between the two vignettes. The educational researchers probably regard themselves as less ambivalent and more supportive of what outsiders might see as 'one side of the argument'. Certainly their publications and presentations have continually drawn attention to contesting deficit understandings of occupational mobility (see also Henderson, 2001, 2004, 2005 in relation to equivalent understandings about Australian itinerant farm workers). By contrast, the environmental researcher has worked hard to present "[him]self as a balanced researcher" (Danaher, 2004 , p. 122) and to refrain from aligning himself overtly with a particular viewpoint.

Yet there seem to be more similarities than differences between the vignettes. One such similarity is the cultural dimension of the two studies (although in the whaling study that dimension entails the extra complexity of the researcher working in a country and in a language different from his own). Another similarity is both sets of researchers acknowledging the limits of their own knowledge and capacity for reflexivity. Those limits have been encapsulated in the call for "the development of road maps for 
conceptualising and conducting research - however limited, partial and temporary those road maps might of necessity be" (Anteliz, Danaher \& Danaher, 2001, p. 233). Yet another is that the two vignettes highlighted potential role confusion and overlap. This recalls that the researcher's roles - whether conscious and intentional or otherwise - can include, among others, those of advocacy with or for the group participating in the research, appropriation of that group's difference and/or complicity in perpetuating that group's marginalisation (Danaher, 1998). (See also Harreveld, 2004, pp. 44-46 for a different application of the researcher's roles.) And a final similarity is that both sets of researchers conceive their projects as exhibiting the drawbacks and benefits of strategic uncertainties. This is the situation whereby " $[t]$ he kind of opening which such work attempts is that of the rupture - or interruption and disruption - in the (uncertain) hope that this will generate possibilities for things to happen that are closed off by the epistemologies of certainty..." (Stronach \& MacLure, 1997, p. 5; emphasis in original).

There are therefore several potential developments of the ideas presented in the two vignettes opening this paper. Only one is possible in this text. For that we have selected what we consider the useful and powerful concept of situated ethics (Piper \& Simons, 2005; Simons \& Usher, 2000) as a means of evaluating the values of the researchers and the other research participants in the Japanese non-government organisations and on the Australian showgrounds. This concept is therefore beneficial in interrogating the value of the respective studies in which those values are enacted.

The paper consists of three sections:

- a brief overview of the concept of situated ethics

- the application of that concept to the Japanese environmental politics study

- the application of that concept to the Australian Traveller education study.

We argue that situated ethics is helpful in highlighting some of the complexities, nuances and subtleties underpinning the respective researcher's relations with other participants. It is consequently valuable in acknowledging the central contribution that researcher subjectivity plays in assessing claims about the significance of a research project.

\section{Situated Ethics}

Ironically one of the most telling encapsulations of the notion of situated ethics did not refer to the term at all. According to Small (2002), "New and unfamiliar situations require us to extend our existing abilities, not to return to first principles and set up formal codes" (p. 89). We should say at the outset that we do not necessarily disparage "first principles" or oppose "formal codes", but rather that we decline to give them intellectual priority in analysing educational research ethics. What attracts us to situated ethics is its focus on "understanding ethical practice as contingent and located in the specific power grids of particular institutions" (Anteliz \& Danaher, 2005, p. 3) and situations. For us, this focus unfreezes ethics and highlights its fluid and transitory character, as well as its intersection with myriad other forces of power and meaning making. (See Danaher [2006] for an application of the same concept to an interrogation of a postgraduate course in educational research ethics and data management.) 
More specifically, Simons and Usher (2000) asserted that "...ethical principles are mediated within different research practices and these take on different significances in relation to those practices" (p. 1). For them, "A situated ethics is local and specific to particular practices. It cannot be universalized..." (p. 2). From this derives ineluctably "...the inescapable necessity for making ethical decisions and the difficulty and complexity of such decision-making in situations where recourse cannot be had to indubitable foundations and incontrovertible principles" (p. 3). Furthermore (foreshadowing Small [2002]): “...making ethical decisions, in whatever situated context, is a process of creating, maintaining and justifying an ethical integrity that is more dependent on sensitivity to politics and people than it is on ethical principles and codes" (p. 11). Finally, Simons and Usher provided a useful synthesis of their understanding of situated ethics in their summary of the major common themes in their edited book deploying the concept:

- "the challenge to universal principles and codes;

- the importance of being sensitive to socio-political contexts;

- the scope for being fair to disadvantaged groups; and taking account of the diversity and uniqueness of different research practices" (p. 11).

Further comprehension of the potential utility of situated ethics can be gleaned from the following four examples of topics discussed in the book:

- “...where responding to one stakeholder's vested interest would inevitably conflict with meeting the needs of others" (Simons, 2000, p. 43)

- "...the possibility of conducting research with emancipatory intent while being funded, albeit indirectly, by government" (Johnston, 2000, pp. 72-73)

- whether "....all deceit [is] morally equal and to be equally condemned?" (Prosser, 2000, p. 121)

- " $[\mathrm{t}]$ he ethical impact of...misuses of quantitative procedures can be to exaggerate the accuracy or explanatory power of the data, or even to derive conclusions that are deceptive or untrue" (Jones, 2000, p. 153).

We take from these disparate examples and the preceding summation that situated ethics can assist us in what we have elicited as three fundamental processes in evaluating the values framing a research project and the value of that project:

- unfreezing the elements of educational research ethics to highlight their fluidity, transitoriness and unpredictability

- unsettling the taken for granted assumptions about the operation of such ethics in specific projects

- interrogating the relationships and situations in which project-specific ethics are enacted.

We see these three processes as interdependent and iterative rather than as linear and lock step. For example, unfreezing might relate to identifying aspects of relationships with research participants that might otherwise assume their homogeneity and might thereby essentialise them, keeping their subjectivities 'frozen'. Thus unfreezing can potentially refer to formal and explicit and/or to informal and implicit components of educational research. Unsettling might include reflecting on the strategies of homogenisation and 
essentialisation at a broader level, looking for instance at other groups subject to those strategies and at why those strategies endure. Interrogating might include looking carefully at documentation such as consent forms and interview schedules for evidence of resilient assumptions that the participants in the particular study will automatically exhibit certain kinds of behaviours because of their assumed homogeneous characteristics. While it is useful to separate the processes analytically, in practice they often spill over into, and hopefully confirm and support, one another. We turn now to observe these processes at work in our respective studies.

\section{Researching Japanese Environmental Politics}

The link between the first vignette and the three processes underpinning situated ethics identified above is centred on the first author's changing stance on the whaling debate in Japan. This link is therefore focused on his relations with the various participants and stakeholders in that debate. That stance is still in a state of flux and amenable to ongoing reflection and review. Nevertheless it has shifted from determined opposition to whaling to a more nuanced understanding of the complexities of the debate and the significance of those complexities in Japanese society writ large and in research into Japanese environmental politics more specifically.

\section{Unfreezing the elements of educational research ethics}

Given this shift, it is not surprising that the process of unfreezing in this case was concentrated on the first author's growing understanding that the foundation of his opposition to whaling was not as set or secure as he had at first imagined. As he conducted interviews with members of the pro-whaling lobby and the government departments most closely concerned with the debate, he became increasingly aware that there were multiple perspectives and varied shades of meaning about the issue. These perspectives and shades of meaning contrasted with the 'pro' and 'con' polarities that he had previously assumed. Moreover, he became interested in tracing some of the nuances and subtleties in those perspectives and shades of meaning to a complex array of cultural, economic, environmental, historical and political factors. For example, there were unexpected diversities of opinion within government departments. There were also unusual sympathies and even alliances across organisations that might otherwise be expected to be oppositional to one another. (An example of this was some Japanese politicians and bureaucrats holding anti-whaling views and the Japan section of the World Wildlife Fund publicly advocating some form of sustainable whaling.)

Underlying this unanticipated questioning of his own stance on Japanese whaling was the unfreezing of the author's relationships with the various participants in his research. Specifically he moved from a position of automatic empathy with the anti-whaling lobby and equally automatic antipathy to the pro-whaling lobby to one of respectfully seeking to understand the thinking of as many stakeholder individuals and groups as possible. This ethical shift was in response to his research project being situated at the intersection of powerful emotions and forces in a country both fascinating and unfamiliar to him. This shift was neither easy nor clear, but in retrospect it was probably necessary to enable him to address his research questions from a wider perspective than his original stance would have allowed. This shift was less a move away from privileging whales over those who 
hunted them than an acknowledgment of his ethical responsibility to all participants in his research, regardless of their particular location on the pro-anti-whaling continuum.

\section{Unsettling assumptions about ethics in specific projects}

This process of unfreezing both contributed to and was accompanied by a corresponding process of unsettling the first author's assumptions about the ethics of his particular research project. Part of that unsettling centred on the purposes of his research. Was that research intended to advocate for one or more positions in the whaling debate, to present a balanced and neutral view of the major positions in that debate, to identify possible synergies and potential resolutions among seemingly irreconcilable positions and/or to educate proponents of different positions about the stances of adherents of other positions? By the end of his doctoral study he had moved from wanting to be an advocate to seeking to present a balanced, even if not wholly neutral, view. His postdoctoral research has increasingly alerted him to the existence and value of other possible purposes, including enhancing dialogue and sharing understanding.

This shift has in turn been accompanied by unsettling and changing assumptions about the first author's own power and accountability as researcher. Specifically he began with a sense of powerlessness about being unable to challenge and change Japan's prowhaling activities. That sense has become an increased conviction of agency and responsibility in relation to being part of the complex web of interrelationships that constitutes Japanese environmental politics. This move has paralleled and been fuelled by his becoming increasingly situated and instantiated in relations of reciprocity with representatives from across the environmental political spectrum in Japan. Again situated ethics is helpful in unsettling existing assumptions and developing new aspirations about the researcher's multiple roles and responsibilities.

\section{Interrogating the relationships and situations where ethics are enacted}

For the first author, unfreezing the elements of ethics and unsettling the assumptions about those ethics have combined to facilitate the interrogation of the key relationships and situations within his specific research project. Two examples must suffice. In the first example, he has pointed out some misinformation in the public arena conducted by antiwhaling non-government organisations. This action might be construed as oppositional to the anti-whaling lobby, yet it was actuated by a desire to help that lobby to make its stance as strong and impervious to contestation as possible. In the second example, an anti-whaling scholar privately criticised one of the first author's publications (Danaher, 2002) as being excessively influenced by Japanese Fisheries propaganda.

In combination, these two examples demonstrate three key attributes of the situated ethics of conducting research in an emotionally and politically charged debate such as Japanese whaling. Firstly, being ethically situated sometimes takes the form of being positioned by others according to their respective aspirations and objectives that are not necessarily cognisant of, or interested in, the researcher's own aspirations and objectives. Secondly, situated ethics requires engaging in situ and subsequently with a potentially bewildering array of perspectives and relationships of considerably greater complexity than can be envisaged at the beginning of the research. Thirdly, situated ethics provides a framework 
for the ongoing interrogation of those perspectives and relationships in order to maximise the researcher's agency and room to manoeuvre and hopefully to enhance the benefits of the research for a range of participants and stakeholders.

\section{Researching Australian Traveller Education}

One of the key elements of the discussion of the second vignette in the introduction to this paper was the complexity of the relationships attending the Australian Traveller education research project. The principal groups of potential stakeholders (while acknowledging the diversity of aspiration, experience and worldview within each group) include the following:

- the show children

- their families

- other members of the show community

- staff members of the Brisbane School of Distance Education and currently the Queensland School for Travelling Show Children

- officials in Education Queensland

- the research team

- the research team's students, colleagues and fellow researchers

- the research team's institutions.

The sheer number of these groups and their intersections creates potential misunderstanding and conflict. Nevertheless situated ethics is helpful to the researchers in devising and deploying navigational tools to chart their course as they interact over time and across multiple sites. This assertion can be demonstrated by applying the three processes elicited above as underpinning situated ethics to the second vignette from the introduction.

\section{Unfreezing the elements of educational research ethics}

In hindsight, a notable omission from the discussion among the research team was any appeal to the university human ethics clearances that the team had gained for each stage of the project. This is not to deny the necessity of such clearances, but instead to highlight that they are rarely uppermost in the informal discourse of research team members. This point in turn suggests that formal clearance procedures and the codes of ethics that frame them have specific but limited purposes and they cannot encompass the full range of human interactions related to a project (Small, 2002).

Another dimension of unfreezing the elements of educational research ethics evident in the second vignette was that the only group about whom the research team spoke and thought in terms of its formal position was the Educational Queensland officials whom they had not met previously. The other participants - the members of the show community and the principal and teachers of the Brisbane School of Distance Education - were discussed implicitly as individual human beings. These human beings among other characteristics occupied particular formal positions but also exhibited a wide range of less formal features, such as commitment to the show children's futures and enthusiasm for formal education. This aspect of unfreezing research ethics therefore 
entailed the suspension of formal and official designations of individuals and groups in favour of a more dynamic and nuanced understanding of those individuals and groups.

\section{Unsettling assumptions about ethics in specific projects}

Again in hindsight, it is clear that the following were among the assumptions about ethics that were unsettled in the discussion and its aftermath reported in the second vignette:

- Lines of demarcation between groups of stakeholders are clear cut and transparent.

- The expected roles of different groups of stakeholders are few and predictable.

- The range of views within groups of stakeholders is small.

- The respective interests of different groups of stakeholders are explicitly understood and stable over time and place.

- Different groups of stakeholders have access to roughly equivalent levels of formal and informal power.

- Based on these assumptions, ethical conduct by members of the research team is straightforward to define and affirm.

On the contrary, each of these assumptions was demonstrated to be untenable, at least in some contexts. As with most long-term relationships, the researchers had grown comfortable in their annual research trips to the show. These trips had been interspersed with sporadic contact with the show community and the distance education school (such as sending them copies of research publications, more recently enlarged to writing some of those publications with the principal of the show school). It was only when a difficult decision with potentially disturbing consequences needed to be made that the taken for granted character of that feeling of comfort was displayed and disrupted.

\section{Interrogating the relationships and situations where ethics are enacted}

Unfreezing elements and unsettling assumptions are worthy processes in their own right. They are doubly useful when they are aligned with a process of interrogating the relationships and situations in which research ethics are enacted.

In the case of the second vignette, the second author's immediate and instinctive response when the invitation to attend the meeting with Education Queensland was issued was confirmed through careful discussion with members of the research team. That discussion was predicated on relations of respect, trust and mutual interest that have ensured the continuity of the team - with inevitable changes owing to the relocation and retirement of some members and the entry of others - from 1991 to the present.

It was precisely those same aspects of respect, trust and mutual interest in the researchers' relations with the other stakeholders in the project that animated the research team to reach its decision. In other words, in the specific situation created by the invitation from the show community, it was the relationships between that community and the researchers that provided the framework for decision-making about ethics. This was despite the point that such relationships are inevitably fluid, complex, nuanced and subtle. More broadly, it was those same relationships and the associated subjectivities that rendered explicit and open to scrutiny the multiple values held across and within 
different stakeholder groups. These relationships and subjectivities also vocalised the many voices that allow judgments to be made about the value of the particular research project that create opportunities for those groups to interact and intersect.

\section{Conclusion}

The United States feminist educational researcher Patti Lather (1992, p. 91) reminds us that "educational research is increasingly construed as a value-constituted and valueconstituting enterprise, no more outside the power/knowledge nexus than any other human creation". Lather's own response to this situation has been to seek to enact "an intentionally ambiguous and multi-layered textual practice, ... a bivalent text...that signals tentativeness and partiality" (1994, pp. 53-54).

We see considerable merit in this approach (Danaher, 1998, pp. 57, 66). Nevertheless we assert on the basis of the preceding discussion that situated ethics is also worthy of consideration for possible inclusion in contemporary educational researchers' toolkits for evaluating their own and other research participants' values and in doing so for interrogating and hopefully maximising the value of their research projects. We contend that contesting the automatic scriptural authority of codes of ethics enhances, rather than reduces, the centrality of considerations of ethics in such projects. (At the same time, we recognise the importance of not elevating situated ethics to the status of a metanarrative and of subjecting it to the same kind of interrogation.)

We turn finally to consider the questions framing this special theme issue of the International Journal of Pedagogies and Learning. Rather than taking up one or two of these questions in more depth we have elected to address each of them briefly, derived from our focus on situated ethics:

- How can and should educational researchers position themselves in relation to their research projects?

In the two projects outlined here, the researchers have positioned themselves as key stakeholders with interests (in both senses of that term) in the success of the project. They regard those interests as contextualised and temporary rather than as paramount and permanent, and they accept responsibility for re-evaluating those interests if they conflict with those of other stakeholders.

- Which assumptions, attitudes and values on the part of researchers have been or are likely to be revealed by the design and conduct of their research projects?

The three processes of situated ethics elicited from the literature and applied to the two vignettes include unsettling taken for granted assumptions on the part of the researchers. The vignettes demonstrated that assumptions, attitudes and values both precede and emerge from the researchers' interactions with other participants, making research project design and conduct an ongoing task and a never-ending story.

- In what ways do researchers' values intersect with, and/or are in conflict with, the claimed and actual value of their research projects? 
From one perspective, the relationship between the researchers' values - and those of other research participants - and their projects' claimed and actual value is direct, integral and interdependent. From a very different perspective, that relationship is potentially indirect and antagonistic, with researchers' claims about the significance and utility of their research not necessarily matched by the views of other stakeholders. Part of the key seems to lie with researchers' willingness and capacity to engage in the ongoing reflexivity implied by an acceptance of situated ethics. This willingness and capacity in turn seem to accord with Pring's (2002) identification of 'virtue' in educational research as "the disposition to act appropriately in a particular situation" (p. 124; emphasis in original). In other words, we would argue on the basis of the discussion in this paper that researchers and/or other participants must measure up to the high standards of engagement and reciprocity likely to be required of their espoused value systems. Failure to do so is likely to compromise seriously, if not to flaw fatally, the value of a particular research project.

- What are the implications of recognising researcher identities for contemporary debates about the significance and utility of educational research?

We argue that situated ethics is a timely reminder that the significance and utility of contemporary educational research can be neither assumed nor asserted. Instead this significance and utility must be demonstrated by careful critique of participants' multiple and sometimes competing interests and the extent to which those interests are, and should be, fulfilled. Researcher identity emerges from this as potentially unstable and subject to flow and fluidity, yet by no means values free.

Thus, both in the meeting rooms of non-government organisations in Japan and on the ferris wheels and the merry-go-rounds of showgrounds in Australia, research and researchers' ethics are situated and enacted. In the process, researchers' subjectivities are shaped and reformed as questions about the significance of the projects are asked and answered. The values within, and the value of, researching Japanese environmental politics and Australian Traveller education are subjected appropriately to ongoing evaluation - and situated ethics is one among several potentially valuable resources in that evaluation.

\section{Acknowledgments}

An earlier version of this paper was presented at a writing workshop conducted by the University of Southern Queensland Faculty of Education Postgraduate and Early Career Researcher group on 12 July 2007. The authors are grateful to the workshop participants for their constructive feedback and suggestions. The rigorous feedback of two anonymous referees likewise enhanced the paper's clarity and coherence. The authors retain responsibility for the views expressed here.

\section{References}

Anteliz, E. A., Danaher, G. R., \& Danaher, P. A. (2001). Norias and ferris wheels: Benefits, interests and ethics in researching Venezuelan and Australian fairground people's educational experiences. Queensland Journal of Educational Research, $17(2), 221-236$. 
Anteliz, E. A., \& Danaher, P. A. (2005, September 18). The microphysics and micropolitics of microscopic meanings: Situated ethics and professional workplace pedagogy and learning in Venezuelan and Australian universities. Paper presented at the $2^{\text {nd }}$ international pedagogies and learning conference, University of Southern Queensland, Toowoomba, Qld.

Danaher, M. J. M. (2002, June). Why Japan will not give up whaling. Pacifica Review: Peace, Security and Global Change, 14(2), 105-120.

Danaher, M. J. M. (2003, June). The influences on and effectiveness of environmental policy-making and implementation in Japan: The issue of wildlife preservation. Unpublished Doctor of Philosophy thesis, Faculty of Commerce and Management, Griffith University, Brisbane, Qld.

Danaher, M. J. M. (2004). Moralising risky environments: The ethical and political nature of environmental education research. In P. N. Coombes, M. J. M. Danaher \& P. A. Danaher (Eds.), Strategic uncertainties: Ethics, politics and risk in contemporary educational research (pp. 116-129). Flaxton, Qld: Post Pressed.

Danaher, P. A. (1998). Ethics and researching educational itinerancy. In P. A. Danaher (Ed.), Beyond the ferris wheel: Educating Queensland show children (pp. 57-69). Rockhampton, Qld: Central Queensland University Press.

Danaher, P. A. (2001, March). Learning on the run: Traveller education for itinerant show children in coastal and western Queensland. Unpublished Doctor of Philosophy thesis, Faculty of Education and Creative Arts, Central Queensland University, Rockhampton, Qld.

Danaher, P. A. (2006, November 2). Unde venisti, quo vadis et cui bono?: Situated ethics and negotiated interests in designing an educational research ethics postgraduate course at the University of Southern Queensland, Australia. Paper presented at the 1st University of Southern Queensland Faculty of Education Postgraduate and Early Career Researcher Group research symposium, Faculty of Education, University of Southern Queensland, Toowoomba, Qld.

Harreveld, R. E. (2004). Ethical and political dimensions of strategic risk-taking in research. In P. N. Coombes, M. J. M. Danaher \& P. A. Danaher (Eds.), Strategic uncertainties: Ethics, politics and risk in contemporary educational research (pp. 39-51). Flaxton, Qld: Post Pressed.

Henderson, R. (2001). Student mobility: Moving beyond deficit views. Australian Journal of Guidance and Counselling, 11(1), 121-129.

Henderson, R. (2004). Educational issues for children of itinerant seasonal farm workers: A case study in an Australian context. International Journal of Inclusive Education, 8(3), 293-310.

Henderson, R. (2005, July). The social and discursive construction of itinerant farm workers' children as literacy learners. Unpublished Doctor of Philosophy thesis, School of Education, James Cook University of North Queensland, Townsville, Qld.

Johnston, R. (2000). Whose side, whose research, whose learning, whose outcomes? Ethics, emancipatory research and unemployment. In H. Simons \& R. Usher (Eds.), Situated ethics in educational research (pp. 69-81). London: Routledge/Falmer. 
Jones, K. (2000). A regrettable oversight or a significant omission? Ethical considerations in quantitative research in education. In H. Simons \& R. Usher (Eds.), Situated ethics in educational research (pp. 147-161). London: Routledge/Falmer.

Lather, P. (1992, Spring). Critical frames in educational research: Feminist and poststructural perspectives. Theory Into Practice, 31(2), 87-98.

Lather, P. (1994). Textual strategies and the politics of interpretation in educational research. Australian Educational Researcher, 21(1), 41-62.

Moriarty, B. J., Danaher, G. R., Kenny, M. D., \& Danaher, P. A. (2004, June). Experiences and issues in implementing an educational innovation: Report on research conducted with children and parents in the show community and personnel in the Queensland School for Travelling Show Children and Education Queensland in Brisbane and Southport in August 2003 (50 pp). Rockhampton, Qld: Central Queensland University.

Piper, H., \& Simons, H. (2005). Ethical responsibility in social research. In B. Somekh \& C. Lewin (Eds.), Research methods in the social sciences (pp. 56-63). London: Sage Publications.

Pring, R. (2002). The virtues and vices of an educational researcher. In M. McNamee \& D. Bridges (Eds.), The ethics of educational research (pp. 111-127). Oxford, UK: Blackwell Publishing.

Prosser, J. (2000). The moral maze of image ethics. In H. Simons \& R. Usher (Eds.), Situated ethics in educational research (pp. 116-132). London: Routledge/Falmer.

Simons, H. (2000). Damned if you do, damned if you don't: Ethical and political dilemmas in evaluation. In H. Simons \& R. Usher (Eds.), Situated ethics in educational research (pp. 39-55). London: Routledge/Falmer.

Simons, H., \& Usher, R. (2000). Introduction: Ethics in the practice of research. In H. Simons \& R. Usher (Eds.), Situated ethics in educational research (pp. 1-11). London: Routledge/Falmer.

Small, R. (2002). Codes are not enough: What philosophy can contribute to the ethics of educational research. In M. McNamee \& D. Bridges (Eds.), The ethics of educational research (pp. 89-110). Oxford, UK: Blackwell Publishing.

Stronach, I. M., \& MacLure, M. (1997). Educational research undone: The postmodern embrace. Buckingham, UK: Open University Press. 